\section{Aspartame induces angiogenesis in vitro and in vivo models}

Human and Experimental Toxicology 20I5, Vol. 34(3) 260-265 (C) The Author(s) 2015 Reprints and permission: sagepub.co.uk/journalsPermissions.nav DOI: $10.1177 / 0960327|| 4537535$ het.sagepub.com (SSAGE

\author{
F Yesildal', FN Aydin', S Deveci', S Tekin ${ }^{3}$, I Aydin', \\ R Mammadov ${ }^{4}$, O Fermanli ${ }^{3}$, F Avcu $^{5}, \mathrm{CH}$ Acikel $^{6}$ \\ and T Ozgurtas'
}

\begin{abstract}
Angiogenesis is the process of generating new blood vessels from preexisting vessels and is considered essential in many pathological conditions. The purpose of the present study is to evaluate the effect of aspartame on angiogenesis in vivo chick chorioallantoic membrane (CAM) and wound-healing models as well as in vitro 2,3bis-2H-tetrazolium-5-carboxanilide (XTT) and tube formation assays. In CAM assay, aspartame increased angiogenesis in a concentration-dependent manner. Compared with the control group, aspartame has significantly increased vessel proliferation $(p<0.001)$. In addition, in vivo rat model of skin wound-healing study showed that aspartame group had better healing than control group, and this was statistically significant at $p<0.05$. There was a slight proliferative effect of aspartame on human umbilical vein endothelial cells on XTT assay in vitro, but it was not statistically significant; and there was no antiangiogenic effect of aspartame on tube formation assay in vitro. These results provide evidence that aspartame induces angiogenesis in vitro and in vivo; so regular use may have undesirable effect on susceptible cases.
\end{abstract}

\title{
Keywords
}

Aspartame, angiogenesis, CAM assay, tube formation, skin wound healing

\section{Introduction}

Aspartame is a food additive marketed under a few brand names, and it has subsequently been approved for use in a number of food products including multivitamins, fruit juices, stick-type confections, breath mints, and iced tea. ${ }^{1}$ Aspartame is a methyl ester of an aspartic acid and phenylalanine dipeptide, used as a synthetic nonnutritive sweetener in over 6000 products across 90 countries worldwide. ${ }^{2}$ Although aspartame is used in many products for nearly 30 years, it is not clearly established whether it has an undesirable effect. Recent study suggests that useable aspartame extracts have angiogenic activity in vitro. ${ }^{3}$ Angiogenesis is thought to be important in some pathological processes such as chronic inflammatory diseases, psoriasis, diabetic retinopathy, and some cancers. ${ }^{4,5}$ If aspartame has a possible inducing effect on angiogenesis, it may have unfavorable long-term results on these patients. Therefore, we aimed to examine the effects of aspartame on angiogenesis in vivo chorioallantoic membrane
(CAM) model and rat model of skin wound healing; in addition, in vitro 2,3-bis- $2 H$-tetrazolium-5carboxanilide (XTT) assay and endothelial cell tube formation assay were also studied.

'Department of Biochemistry, Gülhane Military Medical Academy, Ankara, Turkey

${ }^{2}$ Department of Pathology, Gülhane Military Medical Academy, Ankara, Turkey

${ }^{3}$ School of Medicine, Gülhane Military Medical Academy, Ankara, Turkey

${ }^{4}$ National Nanotechnology Research Center, Bilkent University, Ankara, Turkey

${ }^{5}$ Department of Haematology, Gülhane Military Medical Academy, Ankara, Turkey

${ }^{6}$ Department of Public Health and Biostatistics, Gülhane Military Medical Academy, Ankara, Turkey

\section{Corresponding author:}

T Ozgurtas, Department of Biochemistry, Gülhane Military Medical Academy, Kecioren, Ankara 060 10, Turkey.

Email: chem352000@yahoo.com 


\section{Materials and methods}

\section{Aspartame solution}

Aspartame was purchased from Bilim Pharmaceuticals Corp. (Istanbul, Turkey). For XTT assay, various aspartame solutions were prepared with serial dilutions from a stock solution of $1 \mathrm{mM}$, which was prepared by dissolving $6 \mathrm{mg}$ aspartame in a final volume of $20 \mathrm{~mL}$ solution. For other models, a stock solution of $100 \mathrm{mM}$ aspartame was prepared and various concentrations were used with dilutions.

\section{Cell viability assay}

Cell viability was evaluated using the XTT method. Human umbilical vein endothelial cell (HUVEC; $100 \mu \mathrm{L}$ ) suspensions were plated in 96-well flatbottom tissue culture plates at a density of $4 \times 10^{4}$ cells/well. The cells were allowed to attach to the well overnight and then treated with $100 \mu \mathrm{L}$ of aspartame solution at various concentrations $(20,40,60,80$, and $100 \mu \mathrm{M}$ ) for $24-48 \mathrm{~h}$. Then, $50 \mu \mathrm{L}$ of XTT reagent solution (Biological Industries, Israel) was added to each well, and then the plate was incubated in a humidified carbon dioxide incubator at $37^{\circ} \mathrm{C}$ for $2-4 \mathrm{~h}$. Control wells were the wells containing the cells and the blank background. Absorbance was read at $450 \mathrm{~nm}$ in an enzyme-linked immunosorbent assay plate reader (model ELx 800 bioelisa microplate reader; Biokit, Spain), and the results were expressed as percentage variation with respect to controls. The cell viability was repeated in triplicate with three independent experiments.

\section{In vitro endothelial cell tube formation assay}

BD Matrigel (BD cat. no.: 354234, USA; $50 \mu \mathrm{L}$ ) matrix was plated in 96-well flat-bottom cell culture cluster plates. After incubating for $30 \mathrm{~min}, 50 \mu \mathrm{L}$ HUVEC $(10,000$ cells/well) and $20 \mu \mathrm{L}$ of $20 \mathrm{mM}$ aspartame solution were placed on matrigel. Control group was prepared by following the same procedure as mentioned previously except aspartame solution. The plate was incubated at $37^{\circ} \mathrm{C}$ for $16-18 \mathrm{~h} .{ }^{6}$ Following incubation, the plated wells were photographed, and the results were evaluated.

\section{CAM assay}

Angiogenesis was evaluated in vivo using the CAM assay. Atak-S fertilized chicken eggs were obtained from Poultry Institution (Ankara, Turkey) and incubated at $37^{\circ} \mathrm{C}$, and $85-90 \%$ of relative humidity were maintained throughout the experiment.

Aspartame with 6, 15, 30, and $60 \mathrm{mM}$ concentrations were prepared, and $50 \mu \mathrm{L}$ of each solution was used on CAMs.

Experiments were performed to determine the mode of action of aspartame on vascular development in the sixth day and seventh day on CAM. On the sixth day, between 10 a.m. and 12 p.m., a window was opened on each egg to allow subsequent access to the $\mathrm{CAM}$ and $50 \mu \mathrm{L}$ of test solution was placed on the surface of each $\mathrm{CAM}^{7}$ Some control CAMs received phosphate-buffered saline (PBS), and then all the eggs were sealed with a transparent tape. On day 7, CAMs were screened and taken pictures using a computeraided stereomicroscope (model S6D; Leica Microsystems, Heerbrugg, Switzerland). The captured images were processed with the software Leica Application Suite V4 Automated Image Analysis (Leica Microsystems). Finally, the increase in vessel formation was scored. ${ }^{8}$

\section{Rat model of skin wound healing}

Male Sprague Dawley rats, aged 8 weeks and weighing 200-250 g, were used for this model. They were anesthetized by intraperitoneal injection of ketamine $(90 \mathrm{mg} / \mathrm{kg})$ and xylazine $(10 \mathrm{mg} / \mathrm{kg})$. Before excision, the surgical area, which is the skin over the dorsal area, was shaved off and disinfected with $70 \%$ ethanol. With the help of a biopsy punch and dissecting scissors, two round sections of $5 \mathrm{~mm}$ diameter full thickness skin were excised from each rat. ${ }^{9}$ Each rat had two groups of wounds: control wound (treated with PBS) and aspartame-treated wound. Aspartame-treated wounds received $50 \mu \mathrm{L}$ of $50 \mathrm{mM}$ aspartame solution. The same treatment protocol was applied for 7 days. On day 8 , the surface area of each wound was calculated and the wounds were harvested. All specimens were fixed in $10 \%$ formalin. After getting thin perpendicular sections, embedding in paraffin and deparaffinization procedures were carried out, and the specimens were stained with hematoxylin and eosin in Department of Pathology of Gülhane Military Medical Academy. Histopathological examination for all slides was carried out under a light microscope by a pathologist blinded to the groups. The wound-healing process was scored according to the following parameters: reepithelization, granulation tissue formation, collagen deposition, inflammatory cells, and angiogenesis. ${ }^{10,11}$ Also, the wound areas were statistically compared. The 


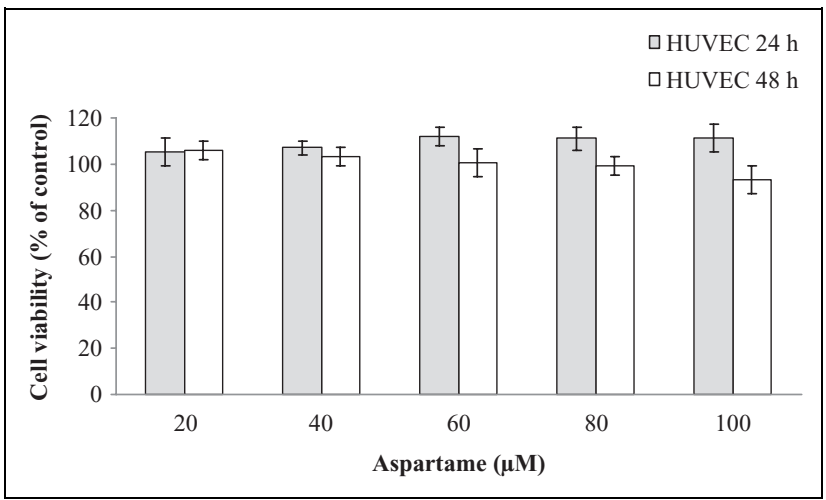

Figure I. Cell proliferation of HUVECs under aspartame incubation (cell viability was indicated as percentage of control). HUVECs: human umbilical vein endothelial cells.

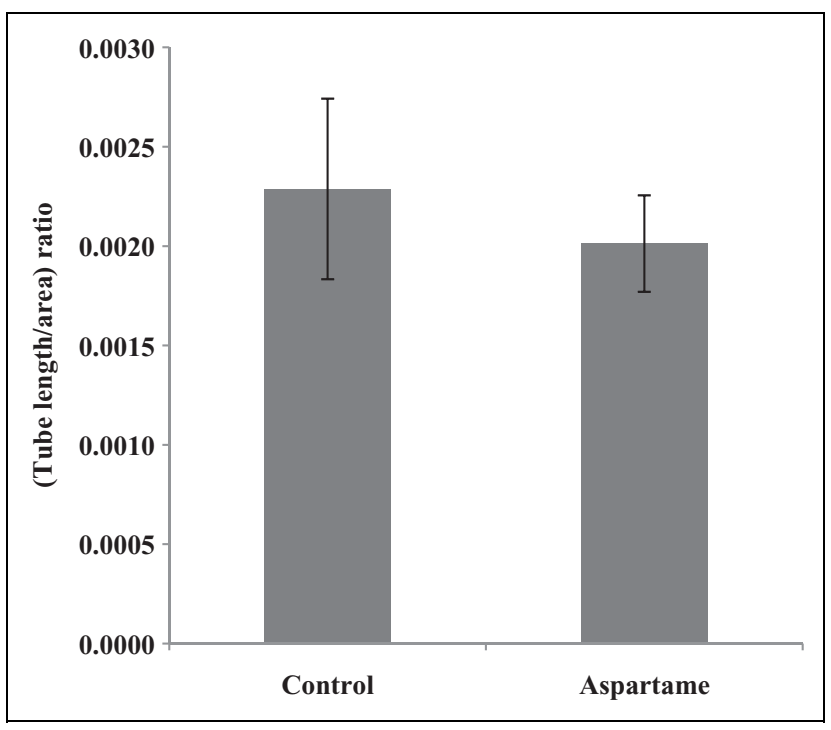

Figure 2. Ratio of tube length to area under aspartame incubation and control.

procedures in this study were approved by the Local Animal Ethics Committee.

\section{Statistics}

The statistical analysis was carried out using Statistical Package for the Social Sciences software for Windows, Version 15.00 (SPSS Inc., Chicago, Illinois, USA). The value of $p \leq 0.05$ was considered statistically significant.

\section{Results}

\section{Cell viability assay of aspartame}

HUVECs were incubated with increasing doses of aspartame for 24-48 h, and cell viability was
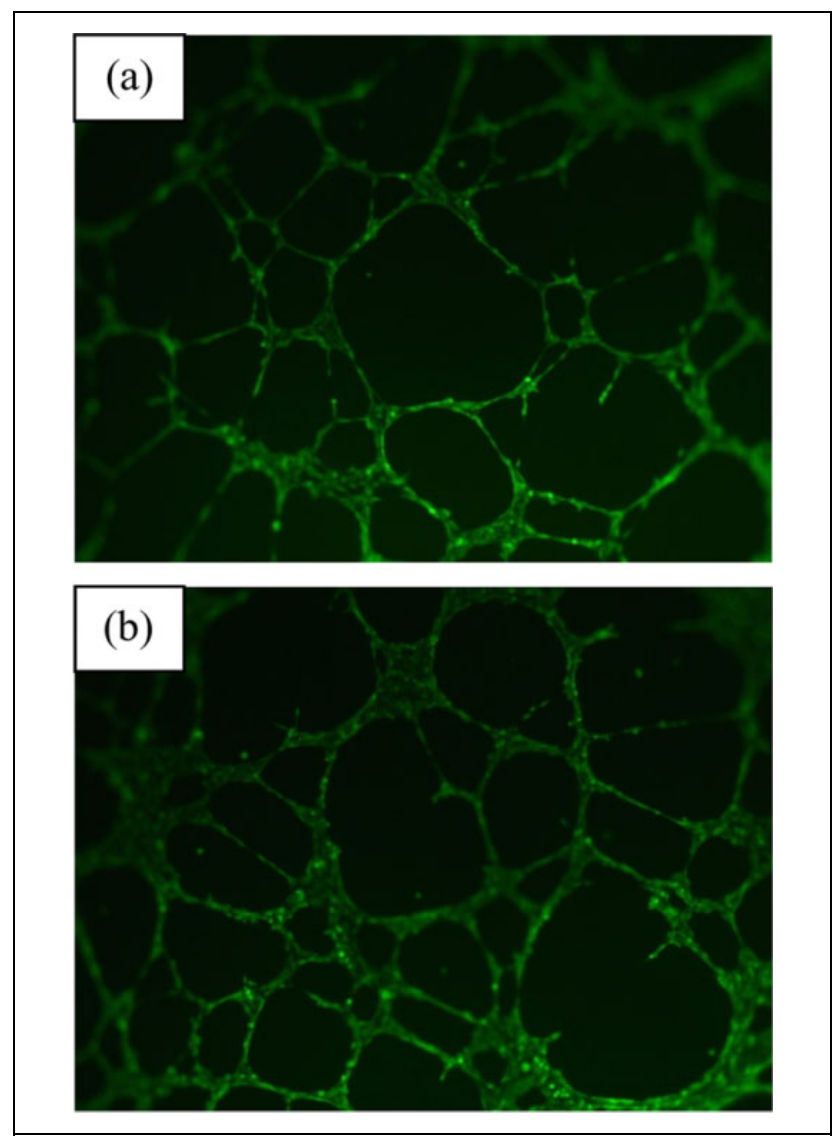

Figure 3. Tube formations of control group (a) and under aspartame incubation (b).

observed with the XTT assay. There is a slight proliferative effect on HUVECs in the presence of aspartame for $24 \mathrm{~h}$, but it was not statistically significant (Figure 1).

\section{Effect of aspartame on tube formation}

In the tube formation assay, on the 18th hour of incubation, the results were evaluated. Comparing the tube length/area ratio values of control and aspartame groups, there was no significant statistical difference. So, it was found that aspartame had no antiangiogenic effect (Figures 2 and 3).

\section{Aspartame induces angiogenesis on CAM}

To determine the mode of action and dose dependency of drug during days 6 and 7 on CAMs, we applied various concentrations of aspartame solution to CAMs on day 6 and evaluated their effects on CAM vessels growth, angiogenesis on day 7. On day 7 , the treatment of CAMs with aspartame solutions caused a significant dose-dependent increase 

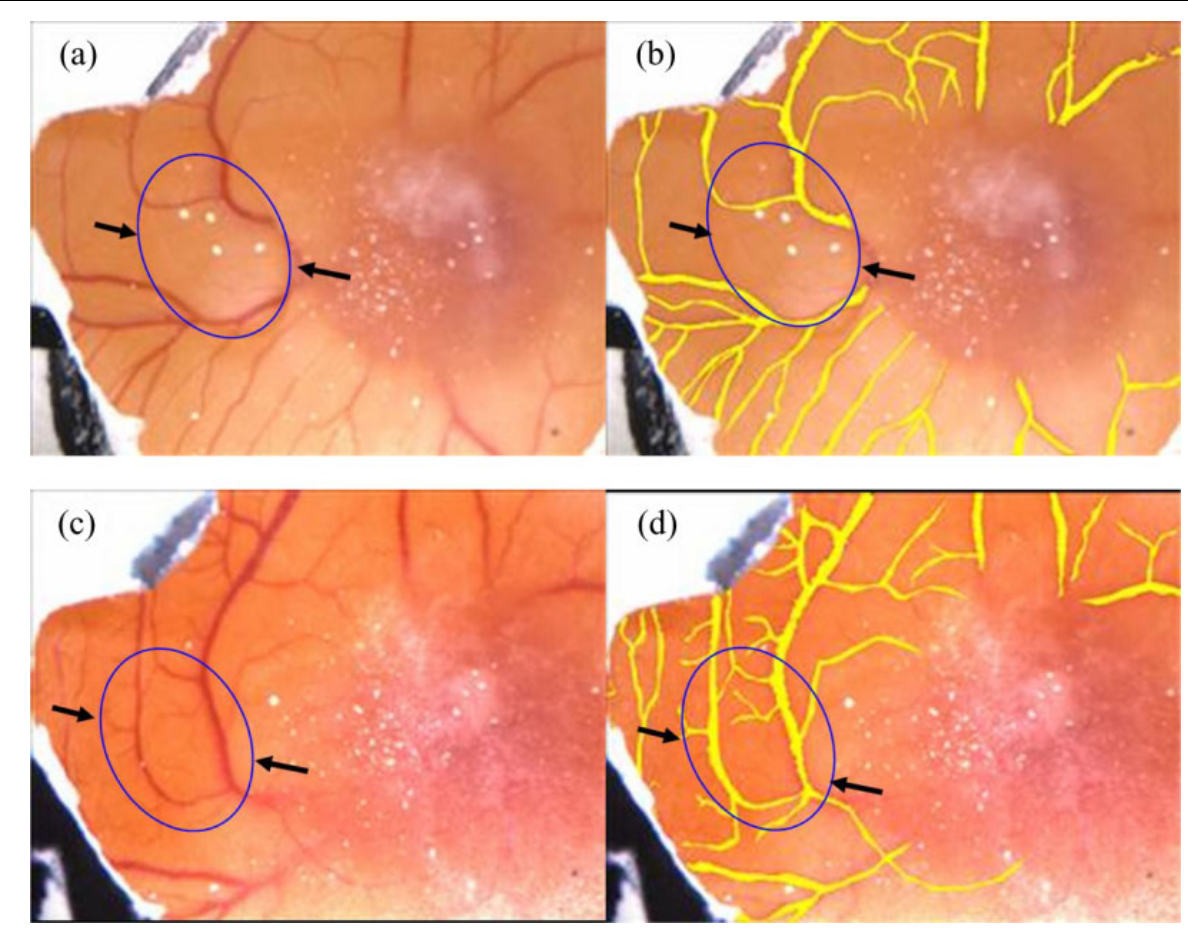

Figure 4. Effect of aspartame solution on CAM before (a) and after $24 \mathrm{~h} \mathrm{(c).} \mathrm{In} \mathrm{images} \mathrm{(b)} \mathrm{and} \mathrm{(d),} \mathrm{the} \mathrm{same} \mathrm{vessels} \mathrm{with}$ (a) and (c) were highlighted with yellow to be seen clearly. CAM: chorioallantoic membrane.

Table I. Macroscopic evaluation of the effect of aspartame treatment on CAM.

\begin{tabular}{llcccc}
\hline & & \multicolumn{4}{c}{ Efficacy } \\
\cline { 3 - 6 } Group & & Ineffective & +1 & +2 & Total \\
\hline Control & $n$ & 5 & 0 & 0 & 5 \\
& $\%$ & 100.0 & 0.0 & 0.0 & 100.0 \\
$6 \mathrm{mM}$ & $n$ & 4 & 0 & 0 & 4 \\
& $\%$ & 100.0 & 0.0 & 0.0 & 100.0 \\
$15 \mathrm{mM}$ & $n$ & 3 & 2 & 1 & 6 \\
& $\%$ & 50 & 33 & 17 & 100.0 \\
$30 \mathrm{mM}$ & $n$ & 2 & 2 & 1 & 5 \\
& $\%$ & 40 & 40 & 20 & 100.0 \\
$60 \mathrm{mM}$ & $n$ & 0 & 3 & 2 & 5 \\
& $\%$ & 0 & 60 & 40 & 100.0 \\
Total & $n$ & 14 & 7 & 4 & 25 \\
& $\%$ & 56 & 28 & 16 & 100.0 \\
\hline
\end{tabular}

CAM: chorioallantoic membrane.

in CAM vascular area. The increase in vessel formation was scored. ${ }^{8}$ While physiological angiogenesis was observed in the form of some allantoic vessels in the control group (score 0), a significant increase in CAM area of eggs treated with aspartame solution was appreciable macroscopically $($ score +2$)$. Significant growth was seen for $60 \mathrm{mM}$ aspartame solution.
In affected CAMs, the vessels were thicker and showed more branching (Figure 4). Efficacy was not enough for low doses; while there was a significant increase for high doses in comparison with the control group. Aspartame caused a significant increase in blood vessels when compared with the control group. However, the lower doses of drug did not show discernible effect on blood vessel pattern.

The efficacies at different doses were compared using $\chi^{2}$ test, and there was a statistically significant difference (Yates correction $\chi^{2}=10.60, p=0.001$ ). The efficacy of increasing dose was evaluated with Spearman's correlation test and a strong relation was found ( $r=0.704, p=0.001)$. Macroscopically evaluated results of CAMs are shown in Table 1.

\section{Aspartame may have a healing effect on wounds by angiogenesis}

Aspartame-treated wounds were found to heal better than the control group. For control group, mean for wound surface area was found as $32.40 \pm 5.58$ $\mathrm{mm}^{2}$, and for aspartame group, the mean was 21.25 $\pm 2.59 \mathrm{~mm}^{2}$. According to the results of independent samples $t$ test analyses, the two groups were found to be significantly different in wound healing $(p<0.05)$, and aspartame had a better healing effect. 


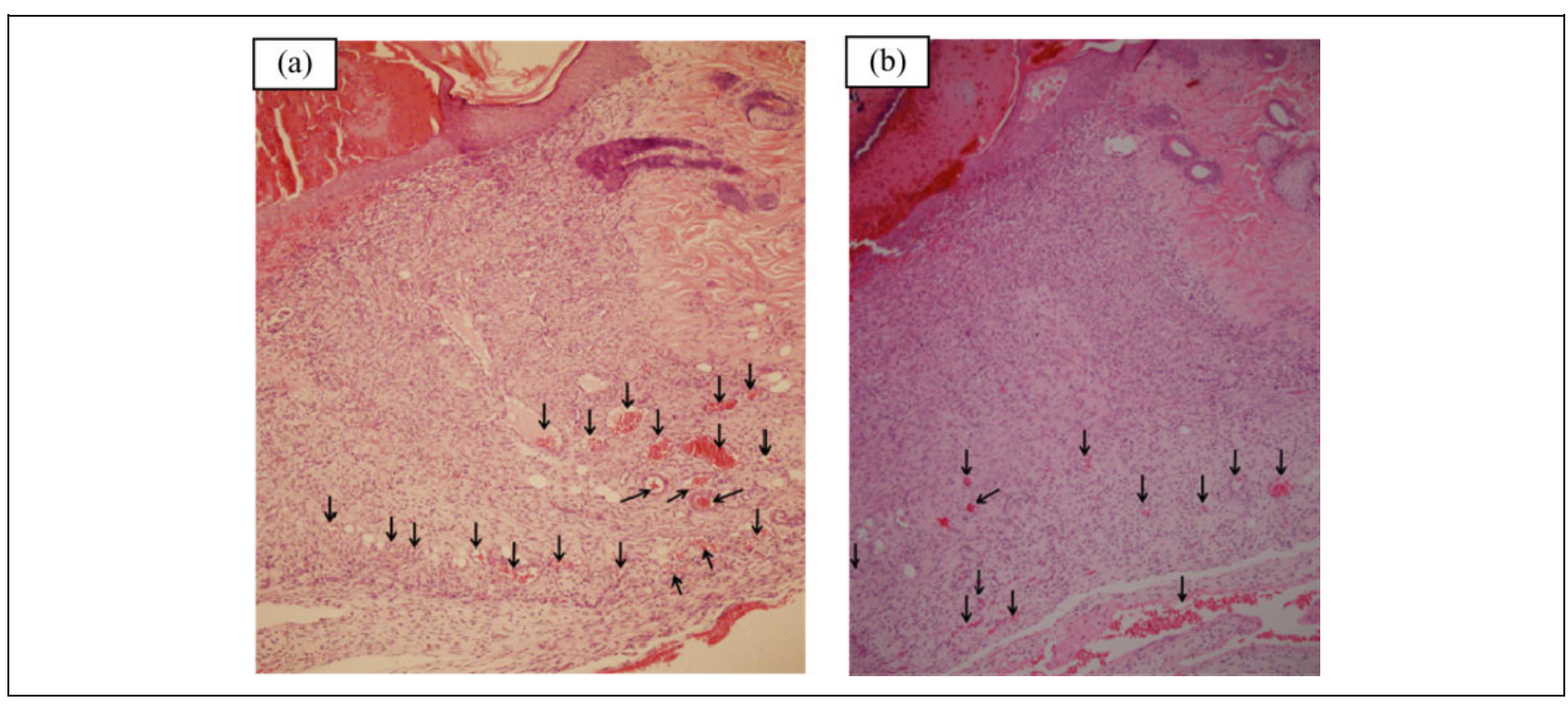

Figure 5. Aspartame-treated wounds (a) showed better angiogenesis and thus better healing compared with the control group (b). Vessel formation seems to be much more in (a) than that of (b).

Histopathological examination showed that aspartame-treated wounds had better healing (Figure 5). The thickness of granulation tissue and collagen deposition were close to each other comparing the control and aspartame groups. All the specimens indicated a complete re-epithelization. Therefore, aspartame-treated wounds showed enhanced cellularity and increased angiogenesis compared with the control group.

\section{Discussion}

Artificial sweeteners are added to a wide variety of foods, drinks, drugs, and hygienic products. ${ }^{12}$ Since the introduction of aspartame into the American food supply in 1981, it has grown to become the most widely used and accepted artificial sweetener. Aspartame has been the predominant artificial sweetener in the United States for the past 25 years and is currently found in over 6000 food and beverage products. ${ }^{13}$ Although many scientific papers have reported contradictory data about aspartame's safety, there are few studies explaining the relation between aspartame and angiogenesis. ${ }^{3}$ The strength of this study is the way it shows the effects of aspartame on both in vivo and in vitro models.

In this study, we aimed to explain clearly the relation between aspartame and angiogenesis using both in vivo and in vitro models because aspartame may have a role in many diseases via angiogenesis.

According to the in vitro results of this study, it was clearly seen that aspartame had a mild proliferative effect on HUVECs in cell viability assay, during short exposure times, similar to the results of Alleva et al. ${ }^{3}$ However, these results were not statistically significant.

CAM assay is a widely used in vivo method to analyze the effects of many different molecules on angiogenesis at varied concentrations. In this study, we examined the effects of aspartame at different concentrations $(6-60 \mathrm{mM})$ on CAM assay. We found that aspartame had an angiogenic effect especially at high concentrations compared with the control group and this was statistically significant. Also, we showed the in vivo effects of aspartame on rat model of skin wound healing and aspartame-treated wounds obviously showed better healing at a concentration of 50 $\mathrm{mM}$, and the results were statistically significant. By inducing angiogenic response, aspartame might have a proangiogenic effect on CAM and wound healing model in vivo. Thus, it is believed that aspartame had similar effects on different species and increased angiogenesis. US Food and Drug Administration has set the acceptable daily intake (ADI) of aspartame at $50 \mathrm{mg} / \mathrm{kg}$ of body weight. The European Food Safety Authority has recommended a slightly lower ADI of aspartame at $40 \mathrm{mg} / \mathrm{kg}$. Aspartame concentrations used in our in vivo models were much lower than these recommended limits. In addition, our results showed that increasing concentrations of aspartame had stronger angiogenic effects. Past studies claimed that aspartame induces regenerative cytokine production leading to the activation of mitogen-activated protein kinases and resulting in 
the formation of new blood vessels. ${ }^{3}$ In our opinion, a change on angiogenic switch with aspartame might play an important role in neovascularization.

There are many contradictory studies about aspartame and its negative effects on health. ${ }^{14,15}$ Many diseases such as Alzheimer's, phenylketonuria, congenital defects, some types of cancer, lupus, and multiple sclerosis are thought to have possible relation with aspartame. ${ }^{16}$ The results of this study, which aims to indicate the relation between aspartame and angiogenesis, showed that aspartame might have an inducing effect on angiogenesis in vitro and in vivo models. Long-term aspartame intake may have unfavorable results on patients with diseases; those pathologic bases are related to angiogenesis. Therefore, other detailed studies, such as tumor models, are needed for a final decision about worldwide usage of aspartame.

\section{Acknowledgment}

The authors would like to give special thanks to Ozlem Bitisik from Bilim Pharmaceuticals Corp. (Istanbul, Turkey) for providing aspartame.

\section{Conflict of interest}

The authors declared no conflicts of interest.

\section{Funding}

This study was supported by Gülhane Military Medical Academy (AR no.: 2012-37).

\section{References}

1. Garriga MM and Metcalfe DD. Aspartame intolerance. Ann Allergy 1988; 61(6): 63-69.

2. Magnuson BA, Burdock GA, Doull J, et al. Aspartame: a safety evaluation based on current use levels, regulations, and toxicological and epidemiological studies. Crit Rev Toxicol 2007; 37(8): 629-727.

3. Alleva R, Borghi B, Santarelli L, et al. In vitro effect of aspartame in angiogenesis induction. Toxicol In Vitro 2011; 25(1): 286-293.

4. Folkman J. Angiogenesis in cancer, vascular, rheumatoid and other disease. Nat Med 1995; 1(1): 27-30.
5. Ferrara $\mathrm{N}$ and Alitalo K. Clinical applications of angiogenic growth factors and their inhibitors. Nat Med 1999; 5(12): 1359-1364.

6. Kubota Y, Kleinman HK, Martin GR, et al. Role of laminin and basement membrane in the morphological differentiation of human endothelial cells into capillary-like structures. J Cell Biol 1988; 107: 1589-1597.

7. Ribatti D, Roncali L, Nico B, et al. Effect of exogenous heparin on the vasculogenesis of the chorioallontoic membrane. Acta Anat 1987; 130(3): 257-263.

8. Knighton D, Ausprunk D, Tapper D, et al. Avascular and vascular phases of tumor growth in the chick embryo. Br J Cancer 1977; 35(3): 347-356.

9. Lee WR, Park JH, Kim KH, et al. The biological effects of topical alginate treatment in an animal model of skin wound healing. Wound Repair Regen 2009; 17(4): 505-510.

10. Wu Y, Chen L, Scott PG, et al. Mesenchymal stem cells enhance wound healing through differentiation and angiogenesis. Stem Cells 2007; 25: 2648-2659.

11. Galeano M, Deodato B, Altavilla D, et al. Adeno-associated viral vector-mediated human vascular endothelial growth factor gene transfer stimulates angiogenesis and wound healing in the genetically diabetic mouse. Diabetologia 2003; 46: 546-555.

12. Rolls BJ. Effects of intense sweeteners on hunger, food intake, and body weight: a review. Am J Clin Nutr 1991; 53(4): 872-878.

13. Butchko HH, Stargel WW, Comer CP, et al. Aspartame: review of safety. Regul Toxicol Pharmacol 2002; 35: S1-S93.

14. Whitehouse CR, Boullata J, and McCauley LA. The potential toxicity of artificial sweeteners. $A A O H N J$ 2008; 56: 251-259.

15. Newman LC and Lipton RB. Migrane MLT-down: an unusual presentation of migraine in patients with aspartame-triggered headaches. Headache 2001; 41: 899-901.

16. Shankar P, Ahuja S, and Sriram K. Non-nutritive sweeteners: review and update. Nutrition 2013; 29: 1293-1299. 
Copyright of Human \& Experimental Toxicology is the property of Sage Publications, Ltd. and its content may not be copied or emailed to multiple sites or posted to a listserv without the copyright holder's express written permission. However, users may print, download, or email articles for individual use. 